University of Nebraska - Lincoln

DigitalCommons@University of Nebraska - Lincoln

2015

\title{
Group composition effects on aggressive interpack interactions of gray wolves in Yellowstone National Park
}

\author{
Kira A. Cassidy \\ Yellowstone Wolf Project, kira_cassidy@nps.gov \\ Daniel R. MacNulty \\ Utah State University, dan.macnulty@usu.edu \\ Daniel R. Stahler \\ Yellowstone Wolf Project \\ Douglas W. Smith \\ Yellowstone Wolf Project \\ L. David Mech \\ USGS Northern Prairie Wildlife Research Center, david_mech@usgs.gov
}

Follow this and additional works at: https://digitalcommons.unl.edu/usgsnpwrc

Cassidy, Kira A.; MacNulty, Daniel R.; Stahler, Daniel R.; Smith, Douglas W.; and Mech, L. David, "Group composition effects on aggressive interpack interactions of gray wolves in Yellowstone National Park" (2015). USGS Northern Prairie Wildlife Research Center. 312.

https://digitalcommons.unl.edu/usgsnpwrc/312

This Article is brought to you for free and open access by the US Geological Survey at DigitalCommons@University of Nebraska - Lincoln. It has been accepted for inclusion in USGS Northern Prairie Wildlife Research Center by an authorized administrator of DigitalCommons@University of Nebraska - Lincoln. 


\title{
Group composition effects on aggressive interpack interactions of gray wolves in Yellowstone National Park
}

\author{
Kira A. Cassidy, ${ }^{a}$ Daniel R. MacNulty, ${ }^{b}$ Daniel R. Stahler, ${ }^{a}$ Douglas W. Smith, ${ }^{a}$ and L. David Mech ${ }^{c}$ \\ aYellowstone Wolf Project, Yellowstone Center for Resources, PO Box 168, Yellowstone National Park, \\ WY 82190, USA, bDepartment of Wildland Resources, Utah State University, 5230 Old Main Hill, \\ Logan, UT 84322, USA, and 'US Geological Survey, Northern Prairie Wildlife Research Center, 8711 \\ 37th St. S.E., Jamestown, ND 58401-7317, USA
}

Received 2 September 2014; revised 7 May 2015; accepted 22 May 2015; Advance Access publication 25 June 2015.

Knowledge of characteristics that promote group success during intraspecific encounters is key to understanding the adaptive advantages of sociality for many group-living species. In addition, some individuals in a group may be more likely than others to influence intergroup conflicts, a relatively neglected idea in research on social animals. Here we use observations of aggressive interactions between wolf (Canis lupus) packs over an extended period and use pack characteristics to determine which groups had an advantage over their opponents. During 16 years of observation in Yellowstone National Park from 1995 to 2010 , we documented 121 interpack aggressive interactions. We recorded pack sizes, compositions, and spatial orientation related to residency to determine their effects on the outcomes of interactions between packs. Relative pack size (RPS) improved the odds of a pack displacing its opponent. However, pack composition moderated the effect of RPS as packs with relatively more old members ( $>6.0$ years old) or adult males had higher odds of winning despite a numerical disadvantage. The location of the interaction with respect to pack territories had no effect on the outcome of interpack interactions. Although the importance of RPS in successful territorial defense suggests the evolution and maintenance of group living may be at least partly due to larger packs' success during interpack interactions, group composition is also an important factor, highlighting that some individuals are more valuable than others during interpack conflicts.

Key words: aggression, Canis lupus, conflict, fighting, sociality, territoriality.

\section{INTRODUCTION}

Many gregarious mammals aggressively defend group territories (Rood 1983; Doolan and MacDonald 1996; Watts and Mitani 2001) with the contest winners usually having numerical superiority over rivals (McComb et al. 1994; Gese 2001; Cant et al. 2002; Mosser and Packer 2009). Although group size relative to an opponent has been proven important to the outcomes of conflicts, the effect of group composition has not been examined, in particular, how group composition can influence the benefits of a larger group or, perhaps more importantly, a group with a numerical disadvantage.

Intergroup aggressive interactions are an important element in the life of social, territorial mammals as they can result in injuries and fatalities to individuals (Mech 1994; Mech et al. 1998; Mosser and Packer 2009) and can result in long-term effects on both groups involved in the interaction (Smith et al.

Address correspondence to K.A. Cassidy. E-mail: kira_cassidy@nps.gov.
2009; Mitani et al. 2010). The loss of adult group members may reduce the competitive strength of the group (Wrangham 1999), and failure to defend against intruders may result in the loss of resources, territory, and the lives of group members. This may eventually lead to group dissolution (Goodall 1986; Packer et al. 1988; Mech et al. 1998; Yellowstone Wolf Project, unpublished data).

Although gray wolves have been extensively studied (Mech and Boitani 2003) and intraspecific strife is often the leading cause of natural mortality (Mech 1977; Mech et al. 1998; Cubaynes et al. 2014), little is known about interpack interactions and aggression. Direct observations of interactions are rare, and few accounts have been described (Murie 1944; Mech 1966; Marhenke 1971; Mech and Frenzel 1971; Mech 1993; Mech et al. 1998). Even less is known about how interpack interactions and aggressive territorial defense are affected by pack compositions and demographics. Although territoriality is an underlying theme in many studies of group-living species, a mechanistic understanding of territoriality, intraspecific aggression, and the effects of group composition and 
interaction location on these contests remains an important gap in current knowledge.

We examine the effects of pack characteristics on the outcomes of aggressive intergroup interactions between gray wolf packs using 16 years of individual-based behavioral observations from 1995 to 2010 following the gray wolf reintroduction to Yellowstone National Park (YNP), Wyoming (Bangs and Fritts 1996; Smith and Bangs 2009). Abundant prey and wide, open valleys for unhindered observation combined with a large number of radio-collared and individually recognizable wolves make this area ideal for observing rare behavior. Wolves live in kin-structured social groups called "packs," and we use both terms "pack" and "group," depending on the context. We recorded several types of interactions (see Methods for classification rules), but only interactions between packs were used for analysis. We posit that pack-pack interactions provide the best data to examine 2 groups contesting resources.

We predicted relative pack size (RPS) would have a strong influence on interaction outcome because a numerical advantage in other species often allows a larger group to defeat a smaller group (Bekoff and Wells 1986; Manson et al. 1991; Wilson and Wrangham 2003). We also predicted that the location of the interaction with respect to each group's territory could be an important variable as residents of many species are more likely to win over intruders (Davies 1978; Cheney 1981; Maynard Smith 1982; Croofoot et al. 2008).

Behavioral differences between males and females suggest that groups having a numerical advantage of the more-aggressive sex may be more likely to defeat their opponents (Krebs 1982; Boydston et al. 2001; Lazaro-Perea 2001; Wilson et al. 2001). We predicted that packs with more adult males would be more likely to win because males are often more aggressive than females (LazaroPerea 2001; Wilson et al. 2001; MacCormick et al. 2012; Wilson et al. 2012; Yellowstone Wolf Project, unpublished data). Wolves are also sexually dimorphic with males that are larger and weighing more than females (Butler et al. 2006; Mech 2006).

We predicted that prime-aged individuals - those at peak physical condition - would be most likely to escalate (initiate or participate in chasing, attacking, or killing opponents) during an interaction, much like free-ranging dogs (Pal et al. 1998) and Japanese macaques (Majolo et al. 2005), and similar to gray wolf hunting behavior (MacNulty, Smith, Vucetich, et al. 2009). Although this aspect has been little studied in other species, we predicted the group with more breeders would have more incentive (the addition of mate defense to territorial defense) to escalate during an interaction (Fashing 2001; Cant et al. 2002).

We discuss the implications of our results with respect to the adaptive value of sociality and the importance of certain individuals. Specifically, certain individuals can have impacts on their group's success greater than a simple numerical advantage and also that the evolution and maintenance of group-living may be driven by larger groups' superior ability to protect themselves and their resources during intergroup aggressive interactions.

\section{METHODS}

\section{Study system}

We collected all data on the Northern Range (NR; $1000 \mathrm{~km}^{2}$ ) of YNP $\left(8991 \mathrm{~km}^{2}\right)$. The NR is defined by the seasonal movements of elk (Cervus elaphus). Elevations vary from 1500 to 2400 m, with high elevations characterized by conifer forests and low elevations by open grass meadows and shrub-steppe vegetation. The area experiences long, cold winters and short, cool summers and features a high wolf density fluctuating between 20 and 98 wolves $/ 1000 \mathrm{~km}^{2}$ with an average of 56 .

Although elk are the wolves' primary prey in the area, other prey residing on the NR include mule deer (Odocoileus hemionus), pronghorn (Antilocapra americanus), bighorn sheep (Ovis canadensis), bison (Bison bison), moose (Alces alces), white-tailed deer (Odocoileus virginianus), and mountain goat (Oreamnos americanus). Other predators include black bears (Ursus americanus), grizzly bears (Ursus arctos), mountain lions (Puma concolor), and coyotes (Canis latrans). Areas within YNP are protected from consumptive human activities such as hunting, and livestock grazing.

\section{Data collection}

Observers recorded wolf behavior during daily tracking of radiocollared individuals. The National Park Service approved all capture and handling protocols in accordance with recommendations from the American Society of Mammalogists (Sikes and Gannon 2011). Because intergroup interactions occurred infrequently and unpredictably, we recorded interactions ad libitum (Altmann 1974) and observed them only in the NR where we could make yeararound observations.

For each intergroup interaction, we recorded: 1) size of both groups, 2) age, sex, color, and breeding-status compositions of both groups, 3) time observation began, 4) time it ended, 5) which group initiated interaction, 6) locations of both groups at the beginning and the end of the interaction, 7) behavior of all individuals in each group related to initiation and participation in the chase, attack, kill, or flight, and 8) results of the interaction: win or loss (see below for definitions). We assigned individuals to age categories based on either known age at time of capture or repeated field observations of individually recognizable animals (i.e., pups: less than 1 year old, yearlings: 1-1.99 years, prime-aged adults: 2-5.99 years, and old adults more than 6 years old).

To understand the influence of group characteristics (size, composition, and interaction location) on the outcome of aggressive interpack interaction, we used generalized linear mixed models with a binomial distribution. To account for unmeasured, idiosyncratic variables associated with certain packs, and repeated measures of some packs, we used the pack identity as a random variable in all models.

We examined only observed interactions to determine a winner and a loser based on which pack displaced the other and randomly chose one side of the pack-pack interactions $(n=121)$ for analysis to eliminate dependence between opponents. We did not analyze the wins and losses of pack-individual and individual-individual interactions as they often included nonaggressive behavior between the individual and some pack members as the loners tried to join packs or breed with their members.

Many times, 2 packs interacted out of sight or during the night, and we only tallied these interactions with certainty if a collared wolf was killed $(n=57)$. We did not use these data in the multivariate analysis but to compare with the model-selection results. When collared wolves were found dead, we performed necropsies as soon as possible to determine cause of death. We confirmed a wolf had been killed by other wolves when it had hemorrhaging caused by puncture wounds of the appropriate size for a wolf (approximately $35-55 \mathrm{~mm}$ between canines) and focused bite-wounds to areas typical of wolf attacks: head, neck, groin, and flanks. We took note of other packs in the area of the mortality (either visually or using 
radio-telemetry signals) to determine the possible attackers. We were often able to deduce the pack responsible for the death of a rival wolf and assigned a level of certainty to the attackers. Definite was if the attackers were observed killing the wolf or located in the immediate vicinity $(\leq 1 \mathrm{~km})$ of the fresh collared-wolf carcass or if GPS-collar locations put attackers at the kill location. Probable was if the attackers were located within $15 \mathrm{~km}$ of the carcass and there was evidence of an interaction (e.g., bark-howling, 1 pack split up and trying to regroup, an ungulate kill made by 1 pack and taken over by another). Possible was if the attackers were within $15 \mathrm{~km}$ of the wolf carcass with no other known packs in the area. Unknown was if the carcass of the wolf was well within its own territory, and there was no evidence of other packs in the area, in areas where we had no knowledge of neighboring packs, or 2 or more packs were nearby, and the identity of the attackers could plausibly be either pack. We only included wolves killed by other wolves if the attackers were known with definite, probable, or possible certainty. We tabulated the typical pack size of both packs (the pack experiencing a mortality and the attackers) based on consistent and recent (within 1 month) sightings of both packs to see if the relationship between RPS and mortality events was similar to RPS and observed success or failure during an interaction.

We used RPS for model selection (RPS - e.g., if packs with 5 and 7 members interact they are assigned RPS scores of -2 and 2 , respectively) and so assigned opponents of equal size zeroes instead of total (numerical) pack size. Total pack size measures do not account for the size of the opponent's group - an important source of data only captured using relative numbers or ratios. We measured demographic categories (e.g., adult males) in the same manner - the number of adult males a pack has relative to the opponent. While developing our analysis methods, we compared RPSs and ratios and found they were highly correlated $(r>0.9)$. Because ratios are more sensitive to total group size changes relative to an opponent and the possible effect of the addition or subtraction of 1 wolf is likely different for a large pack than it is for a small pack, we ran the analysis using ratios and RPSs. We compare the results from both measures and then used RPS to compare with the demographic effects. Because we were also testing for the effects of pack members in certain demographic categories (e.g., adult males), we wanted to use measures that were ultimately comparable.

Prior to testing models, we examined each variable for correlation. Some of the variables were highly correlated $(r>0.70)$ with RPS (males, females, pups, and nonbreeders) and were not included in the full, saturated model. We tested the relative importance of the 4 age variables, the 2 adult sex variables, RPS alone, and residency status.

We started with a saturated, mixed-effects, logistic regression model and used backward stepwise selection to determine the best-reduced model for predicting a successful interaction based on our variables. We dropped nonsignificant variables $(P>0.05)$ individually until a likelihood-ratio test indicated that the fit of the reduced model was significantly worse than that of the previous model containing the dropped variable. Once we reached a reduced model we refitted the omitted variables individually and tested for significance. We also tested for interactions between variables in the best-fit model by adding interaction terms individually and testing for significance. We calculated fitted values from the best-fit model with marginal expectations of the 3 variables averaged over the random effect of pack ID and conditional on the observed variables.

\section{RESULTS}

During >5300 observation days, we recorded 292 intergroup interactions involving 33 different packs: 121 pack-pack (41.4\%), 166 pack-individual $(56.9 \%)$, and 5 individual-individual interactions $(1.7 \%)$. Interactions varied in intensity level. All aggressive interactions reached a chase (the defining characteristic of "aggressive"), $71(24.3 \%)$ escalated to a physical attack, and $12(4.1 \%)$ resulted in a fatality. Most interactions occurred during the fall and winter months when pups are nearly fully grown and travel with the pack. The most active months for aggressive interactions were February (48 [20.1\% of the total interactions]) - the wolf breeding season and the time of year testosterone levels peak (Asa 1997) December (41 [17.0\%], and January (33 [13.8\%]). Few aggressive interactions occurred during summer-June through September $(5-9[2.1-3.8 \%])$ when pups are small and centered at a den.

Pack size $(x=8.07$, standard deviation $[\mathrm{SD}]=4.62)$ ranged from 2 to 22 . The average pack included 2.50 pups ( $\mathrm{SD}=3.13$, range $0-12), 1.95$ yearlings $(\mathrm{SD}=1.91$, range $0-9), 2.75$ prime-aged adults $(\mathrm{SD}=1.67$, range $0-7)$, and 0.59 old adults $(\mathrm{SD}=0.73$, range $0-2)$. When combining yearlings, prime-aged and old adults, packs averaged 2.36 adult males $(\mathrm{SD}=1.44$, range $0-8)$ and 2.91 adult females $(\mathrm{SD}=2.02$, range $0-11)$. Packs averaged 2.31 breeders $(\mathrm{SD}=1.32$, range $0-5)$ and 5.12 nonbreeders $(\mathrm{SD}=4.17$, range $0-19)$.

Winning packs usually had more pack members than did losing packs (average of 9.44 compared with 5.81 wolves), as well as more members in each of the demographic categories: pups (3.20 vs. 1.38), yearlings (2.26 vs. 1.47), prime-aged adults (3.04 vs. 2.30), old adults ( 0.70 vs. 0.40$)$, adult males (2.65 vs. 1.89), adult females (3.32 vs. 2.26), and breeders (2.61 vs. 1.83).

\section{Preliminary model testing}

A model testing the influence of the 4 age classes (pups, yearlings, prime-aged, and old) on winning an interaction resulted in all 4 categories having a positive and significant effect on winning. When we combined the 3 nonpup age categories into "adult" and divided them into males and females, both "adult males" and "adult females" were positive and significant. Winning packs often had RPS values of $>0$ and losing packs $<0$. A model testing the influence of RPS on winning an interaction resulted in RPS being significant. The same effect was found related to ratios with packs having a ratio of more than 1 more likely to win. Resident packs were slightly more likely to win than that of intruding packs but was not significant ( $T=1.5, P=0.067)$. In a model considering residents and intruders, the residents had a positive coefficient $(0.307)$ and intruders negative $(-0.138)$, but both $95 \%$ confident intervals overlapped 0 and were not significant (resident $P=0.486$; intruder $P=0.798$ ).

\section{Multivariate analysis}

Backward stepwise selection results suggested that the combined effects of RPS, relative number of old pack members, and relative number of adult males had the most influence on success during intergroup interactions (Table 1). There were no significant pairwise interactions between terms in the final model. The main effect for RPS suggests that packs larger than their opponents are more likely to win. Specifically, the odds ratio (OR) of RPS is 2.4, meaning the odds of winning increased by $140 \%$ ([OR score -1.00$] \times$ $100=\%$ change in odds of winning) with one additional wolf relative to the opposing pack. Because one additional wolf builds on the previous RPS's compounded rate, adding 3 wolves $(\mathrm{RPS}=3$ ) 
means the odds of winning $\left(2.4^{3}=13.82\right)$ was nearly 14 times greater than for a pack with RPS $=0$.

The relative number of old individuals was also included in the best-reduced model. The OR for this variable was 2.5 and indicated the addition of 1 old wolf increased a pack's odds of winning by $150 \%$. The chances of winning an interaction also increased when the relative number of adult males increased; the addition of 1 relative adult male $(\mathrm{OR}=1.65)$ increased a pack's odds of winning by $65 \%$. We used the best-fit model to predict values for a combination of 2 terms (RPS and adult males, RPS and old adults) by calculating the fitted values - while holding

\section{Table 1}

Best-fit model from backward stepwise selection of saturated model using logistic regression analysis of select variables and successful interactions (WIN) between wolf packs in YNP from 1995 to 2010

\begin{tabular}{lllllrr} 
Variable & Coefficient & SE & $z$ & $P>z$ & \multicolumn{3}{c}{$95 \%$ confidence } \\
& & & & & & \\
\hline RPS & 0.886 & 0.255 & 3.47 & 0.001 & 0.385 & 1.386 \\
Adult males & 0.501 & 0.235 & 2.14 & 0.033 & 0.041 & 0.961 \\
Old adults & 0.918 & 0.468 & 1.96 & 0.050 & 0.002 & 1.835 \\
Constant & 0.139 & 0.648 & 0.22 & 0.830 & -1.131 & 1.410 \\
\hline
\end{tabular}

the other term fixed (Figure 1). This illustrates the effect group composition, in the form of adult males and old adults, can have on RPS with respect to winning an aggressive interaction with another group. Further, for a group to achieve OR of 2 to 1 of defeating an opponent, it would require 1 of 3 options: an increase of 0.70 wolves to the pack, having 0.65 more old adults, or 1.30 more adult males than their opponent (Table 2).

Table 2

Numbers of additional wolves necessary-for the 3 variables in the best model (RPS, old adults, adult males) -in order for a pack to achieve specific $O R(1,2,4,6,8,10)$ for defeating another pack based on data in YNP from 1995 to 2010

\begin{tabular}{llll} 
RPS change & $\begin{array}{l}\text { Ren relative } \\
\text { (when } \\
\text { old adult }=0 \\
\text { and relative } \\
\text { adult male }=0)\end{array}$ & $\begin{array}{l}\text { Old adult } \\
\text { change (when } \\
\text { RPS }=0 \text { and } \\
\text { relative adult } \\
\text { male }=0)\end{array}$ & $\begin{array}{l}\text { Adult male } \\
\text { change (when } \\
\text { RPS = 0 and } \\
\text { relative old } \\
\text { adults }=0)\end{array}$ \\
\hline 1 & 0.00 & 0.00 & 0.00 \\
2 & 0.71 & 0.65 & 1.30 \\
4 & 1.48 & 1.40 & 2.70 \\
6 & 2.04 & 1.92 & 3.50 \\
8 & 2.28 & 2.20 & 4.05 \\
10 & 2.52 & 2.40 & 4.50 \\
\hline
\end{tabular}

SE, standard error.
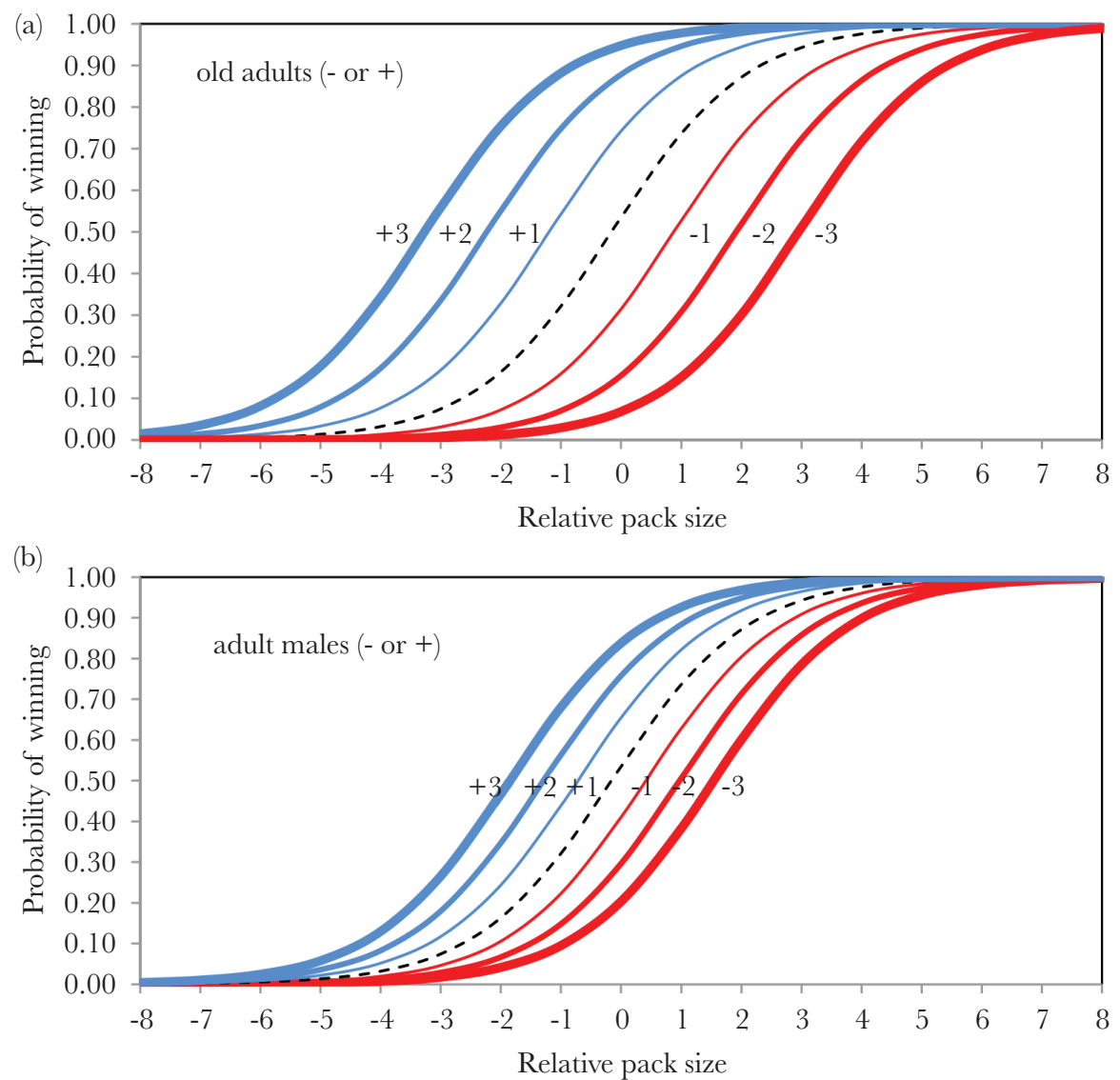

Figure 1

Predicted values for RPS and old adults (a) and RPS and adult males (b) (holding the other term fixed) of the probability of a wolf pack winning an aggressive interpack interaction. Red lines indicate probability of winning while having relatively fewer $(-1,-2,-3)$ old adults (a) or adult males (b) than an opponent. Blue lines indicate probability of winning while having relatively more old adults (a) or adult males (b) than an opponent. Data collected from 1995 to 2010 in YNP. 
Increasing the desired OR of winning to $10-1$, a pack would need either 2.52 more wolves than the opponent, 2.4 more old adults, or 4.5 more adult males. This result highlights the importance of old adults as fewer of them are needed to drastically increase a group's odds of winning (Figure 2). The same analysis was run using ratios instead of RPS and resulted in the same 2 demographic variables (adult male and old adults) in the best-fit model. The OR for the ratio variable was 59.6, meaning that a pack twice the size of their opponent was 59.6 times more likely to win than to lose.

\section{Effects of group size and composition on mortalities}

Packs with a numerical disadvantage (RPS $<0$ ) experienced more intraspecific mortalities (Figure 3). These results support the behavioral data results suggesting that small differences in RPS had a significant effect on success. Furthermore, most packs experiencing a mortality had RPS $>-5$ and $<0$, indicating that packs only slightly smaller than their opponent lose more members than those much smaller $(<-5)$ than their opponent. In addition, packs with $<0$ relative adult males experience more intraspecific mortalities (Figure 3). There was not enough data to calculate mortalities related to the relative number of old adults. Of all packs present in the population (not just those participating in aggressive interactions), the average size difference ranged from 3.7 to 7.8 and averaged 5.2, indicating that pack size was well spread with some large and small packs present each year.

\section{DISCUSSION}

Understanding the evolution of group-territorial defense requires knowledge of the behavioral components of direct interactions and what characteristics of each group determine the outcome. Our study is the first among group-living mammals to find that group composition has effects on successful intergroup aggressive interactions greater than numerical superiority. We offer insight into the mechanics and proximate results of intergroup aggressive interactions among gray wolves when the interactions and group dynamics are directly observed.

\section{Group composition}

Our results demonstrate that certain demographic characteristics of groups can significantly influence the outcome of aggressive interactions in group-living, territorial species beyond numerical effects alone. For wolves, the presence of old adults and adult males was particularly influential.

Research on senescence suggests that animals suffer physical effects due to aging, making them more vulnerable to injury and mortality (Mota et al. 2005; Täubert et al. 2007; Tanaka and Seals 2008; MacNulty, Smith, Vucetich, et al. 2009). We predicted that packs with more prime-aged adults would be more likely to win because prime-aged adults are at their physical peak, as demonstrated in hunting ability (MacNulty, Smith, Vucetich, et al. 2009). This variable was not included in the best model. Age often affects an individual's willingness to participate in aggressive interactions (Pal et al. 1998; Hyman et al. 2004; Majolo et al. 2005; Cafazzo et al. 2010). MacNulty, Smith, Vucetich, et al. (2009) found that age affects individual hunting ability for this wolf population, with a decrease in hunting success at approximately 4 years of age. We do not know if the same decrease is seen in individual fighting ability, but because our results prove that packs with older wolves are more likely to succeed during an interpack interaction, there may be a more-complex relationship between age and fighting ability than age and hunting ability. Although territorial defense may motivate all pack members to fight, mate defense or potential future breeding may stimulate the older wolves (old enough to be reproductive) of a pack to fight beyond the age when they are in prime physical condition, resulting in a later aggressive peak than in hunting or in no peak at all. Investigation into this topic would greatly improve understanding of the motivations of aggression and its relationships to senescence.

Winning packs included more old pack members than their opponents, with the effect being stronger than that for RPS. Packs with the longest tenures were those most likely to include 1 or more pack members in the "old adult" category. Such long-term packs likely possess greater collective experience. Through their experience, older wolves may be better able to assess the fighting ability of opponents before an interaction takes place (through howling communication or scent-mark investigation) and subsequently decide to

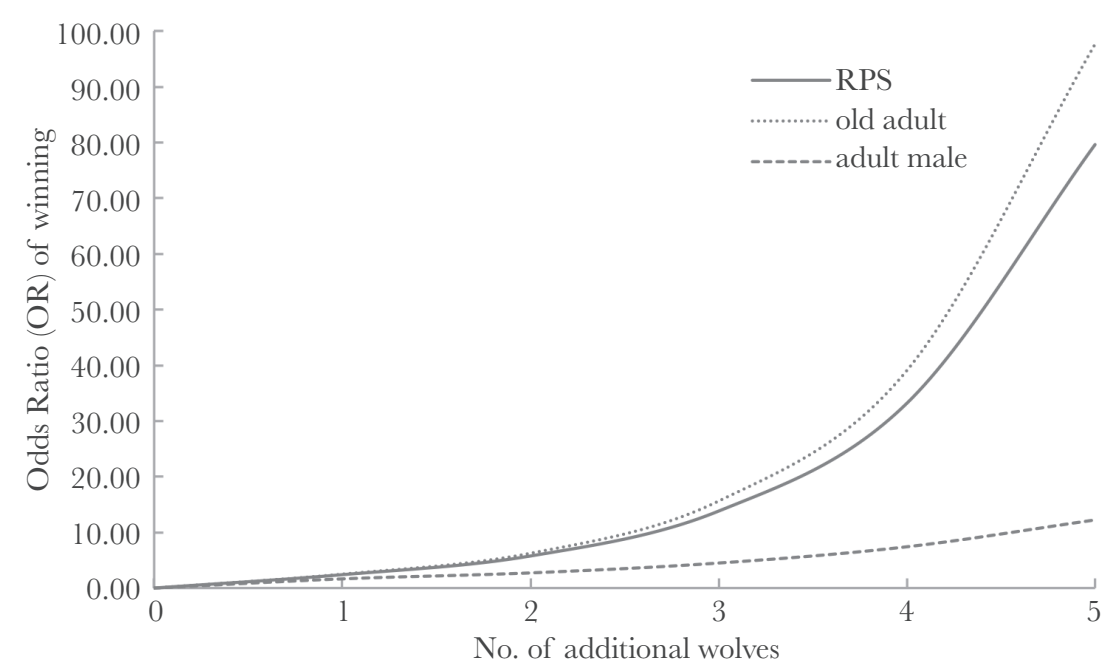

Figure 2

OR of a wolf pack in YNP from 1995 to 2010 winning an interaction based on increases in individuals in each of the 3 variables from the best model (RPS, old adults, and adult males). 


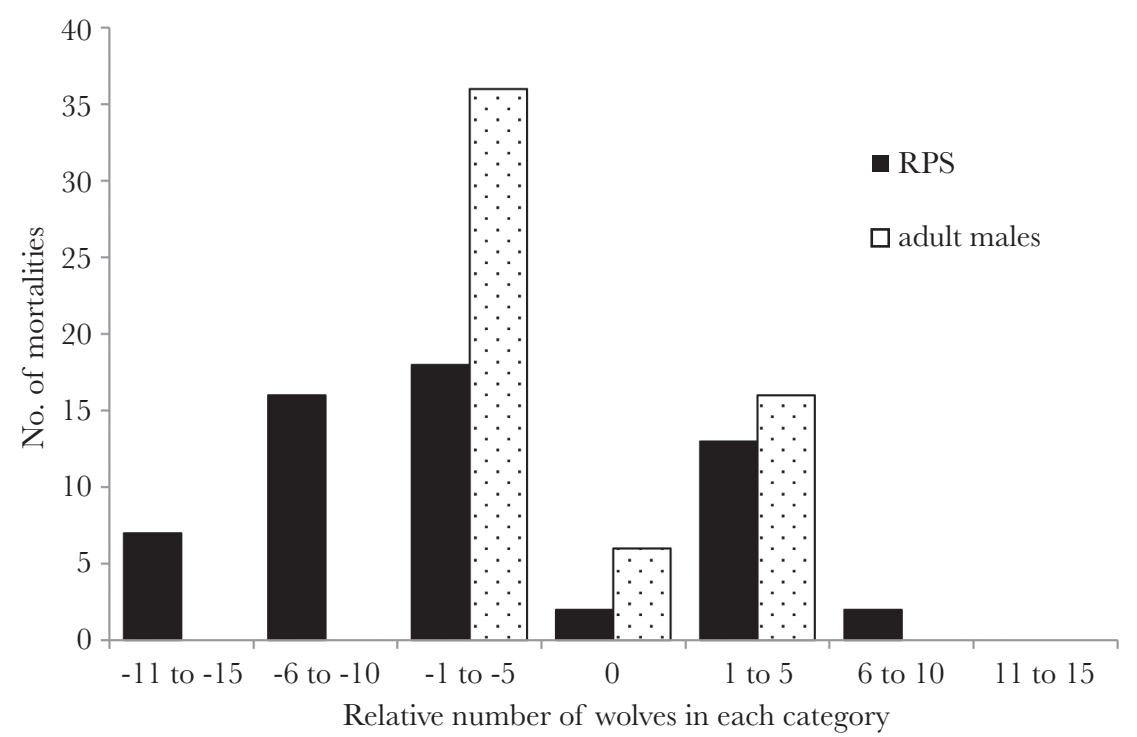

Figure 3

Number of fatal interactions and relative size and group composition of wolf packs in YNP from 1995 to 2010 experiencing an intraspecific mortality (1995-2010). Pack sizes $(n=57)$ and compositions $(n=57)$ are estimates of total pack size and composition based on consistent observations before and after the date of the mortality. Most often a wolf-killed wolf was found based on its mortality signal. We inferred the identity of the attacking pack based on its known location relative to the dead wolf.

engage a pack they feel they can defeat or avoid packs they feel outcompete their own. Likely, the high wolf density, overlap between pack territories, and high rate of aggression allow wolves in YNP's NR to gain greater experience related to interactions with other packs than wolves living in areas of low density. In addition, the terminal investment hypothesis suggests older animals may put more effort into reproduction as their reproductive value begins to decrease (Williams 1966). In the case of wolves, older animals may increase their aggressiveness in order to protect their future reproductive opportunities and as a by-product help their pack defeat their opponent.

Males are more aggressive in several species (Muller and Wrangham 2009; MacCormick et al. 2012), except in some matrilineal, social species such as spotted hyenas (Boydston et al. 2001). Consequently, if pack sizes are equal, the pack with more-aggressive individuals - in this case, adult males - is more likely to win. Sexual dimorphism in wolves may have been an adaptation in response to hunting strategies (MacNulty, Smith, Mech, et al. 2009), competition among males for mating opportunities, or to aggressive groupterritorial defense as packs with more adult males were more likely to be successful. Stahler (2011) demonstrated that reproductive success was higher for females in packs with more males and attributed this result to benefits associated with male effectiveness in hunting, offspring protection, and territorial contests. Our results showing male wolves are advantageous during aggressive interactions provide quantitative support to this conclusion.

Finally, our prediction that packs with more breeders would be more likely to win contests because they are more motivated by territory, and mate defense was not supported by the data. Because breeders were not included in the best-reduced model, possibly breeders do not increase their aggression level simply because they are breeders, or perhaps the division in the types of breeders in a pack (i.e., those who breed within the pack-whose mates are also pack members - and those who breed outside the pack) changes behavior in opposing ways. This difference will be important to recognize in future studies on numerical assessments of pack breeders and their effects on wolf-pack ecology and social behavior.

\section{Residency status}

Residency was not significant at the 0.05 level $(P=0.067)$ and not included among the variables in the best-fit model, contrary to studies on other species (Davies 1978; Krebs 1982; Marden and Waage 1990; Alcock 2001; Johnsson and Forser 2002; Croofoot et al. 2008). Studies showing that territory residents nearly always win contests against intruders have been challenged recently (Hyman et al. 2004; Kemp and Wiklund 2004) suggesting residency for some species may not be as important as previously thought. The insignificance of residency in our study may be due to the relatively small size of the study area, which included the territories of 3-7 packs each year resulting in high wolf density and territory overlap (Smith et al. 2011). Furthermore, a vacancy from the loss of a breeder in 1 pack was usually filled by an individual from a nearby pack (vonHoldt et al. 2008), suggesting that familiarity with a large portion of the study area was high for most packs and an advantage due to landscape familiarity may not exist for this population.

\section{Relative pack size}

Numerical advantages leading to successful intergroup interactions are well documented in other species (Packer et al. 1990; Wilson et al. 2001; Benson-Amram et al. 2011; Wilson et al. 2012), and our work supports these findings. The importance of a numerical advantage in successfully defeating an opponent suggests that territorial defense is an important driver in the evolution and maintenance of group-living among territorial mammals. Although other studies have come to this same conclusion (Mosser and Packer 2009), several other explanations for sociality have been proposed.

Particularly among carnivores, researchers hypothesize that sociality provides hunting (Kruuk 1972; Schaller 1972; Creel S and Creel NM 1995; MacNulty et al. 2012) and survival (Smith et al. 2010) benefits to individuals living in groups. However, kill 
rate does not increase at the same rate as group size (Schmidt and Mech 1997), and for gray wolves in the same population as this study, elk hunting success rates did not increase beyond a pack size of 4 (MacNulty et al. 2012). Average pack size in the NR is 9.9 (Smith et al. 2011); therefore, there must be some other driver influencing pack sizes to be larger than the size that maximizes hunting efficiency. Competition with kleptoparasites is another possible explanation for sociality as smaller (Caraco and Wolf 1975; Cooper 1991; Vucetich et al. 2004; Kaczensky et al. 2005) and intermediate-sized groups (Wilmers et al. 2003) lose more biomass to scavengers.

Wolves are cooperative breeders with packs normally consisting of at least 2 unrelated adults and their offspring from 1 to several years (Mech 1970). This high level of relatedness within groups (vonHoldt et al. 2008), and the assistance of nonbreeders in raising young, has prompted many to suggest kin selection as a possible explanation for sociality (Schoener 1971; Rodman 1981; Schmidt and Mech 1997; Hayes 2000). Stahler et al. (2013) found that the number of pups born to a single female in YNP reached a maximum when adult pack size was 8 . Packs larger than 8 individuals may not produce as many pups, but they may be better at protecting them from harm, given that pup survival increases across all pack sizes (Stahler et al. 2013). Female lions benefit from living in groups because they cooperatively defend their young against infanticide (Pusey and Packer 1994). Assumed to be a rare occurrence in wolf populations, infanticide does occur (Latham and Boutin 2012; Yellowstone Wolf Project, unpublished data). It may be difficult to distinguish pup defense from resource (i.e., prey, territory) defense, as both are often responses to conspecific threats. Likely pup defense and resource defense are intertwined, with success in 1 leading to, or being a significant factor in, success in the other. Our results show that larger pack size is a key factor in a successful aggressive interpack interaction, likely for both of those possible drivers of territoriality.

In addition, our results indicate that packs slightly smaller than an opponent (RPS $=-5$ to 0 ) are the packs most likely to experience a mortality due to intraspecific strife. It is possible a population consisting of similarly sized groups creates a hypercompetitive environment. This idea has not been addressed in group-living species, but fights between single ungulates of similar size are often more intense than fights between pairs with large size differences (Peek et al. 1986). It is also possible that the very smallest packs ( $>5$ wolves fewer than their neighbors) successfully avoid fatal interactions.

\section{CONCLUSIONS}

Consistent with results from many studies on social mammals, we demonstrate that larger relative group size is still an important factor in successful intergroup aggressive interactions. The evolution of sociality among carnivores has many possible, likely interacting, explanations, but the importance of relative group size in successful territorial defense strongly suggests large groups' superior abilities to protect themselves and their resources have been a strong driver in the evolution of group living.

Our study shows that larger groups have a strong advantage during intergroup aggressive interactions in this social carnivore. Furthermore, we demonstrate that group size alone is not the only important factor in intergroup aggressive interactions. In wolves, it appears that group composition, specifically the presence of older adults and adult males, can moderate the effect of group size with respect to successful intergroup aggression and allow smaller groups with certain individuals to defeat larger groups. These results highlight the dynamic effect of group composition on the outcome of interactions by demonstrating that the quality of group members can have important influences on resource protection and, therefore, on many aspects of wolf ecology and life history. With the recent findings that density-dependent intraspecific aggression regulates the survival of northern Yellowstone wolves (Cubaynes et al. 2014), our study demonstrates a socially mediated mechanism by which this vital rate is influenced in this population. Our findings also have management implications for social carnivores where human exploitation may alter group composition through the removal of specific individuals. Such anthropogenic influence could indirectly affect competitive abilities of groups, altering natural social dynamics with fitness and population-level consequences.

\section{FUNDING}

We thank significant donors to the Yellowstone Wolf Project: The Yellowstone Park Foundation, Valerie Gates, Annie and Bob Graham, and Frank and Kay Yeager, as well as the US National Park Service, and the US Geological Survey, and National Science Foundation (DEB-0613730 and DEB-1245373). Any use of trade, firm, or product names does not imply endorsement by the US government.

We would like to thank Erin Stahler, Matt Metz, Rick McIntyre and numerous field technicians for their advice, guidance, and tireless work in data collection and logistics. This work would not be possible without the safe piloting of Roger Stradley from Gallatin Flying Service, Bob Hawkins from Hawkins and Powers, Inc.and Sky Aviation, Inc, and Mark Duffy from Central Copters, Inc. Mike Wilson and Glenn DelGiudice provided valuable insight on early drafts of this manuscript.

Handling editor: Alison Bell

\section{REFERENCES}

Alcock J. 2001. The triumph of sociobiology. Oxford: Oxford University Press.

Altmann J. 1974. Observational study of behavior: sampling methods. Behaviour. 49:227-267.

Asa C.S. 1997. Hormonal and experiential factors in the expression of social and parental behavior in canids. In: Soloman NG, French JA, editors. Cooperative breeding in mammals. Cambridge: Cambridge University Press. p. 129-149.

Bangs EE, Fritts SH. 1996. Reintroducing the gray wolf to central Idaho and Yellowstone National Park. Wildl Soc Bull. 24:402-413.

Bekoff M, Wells MC. 1986. Social ecology and behavior of coyotes. Adv Study Behav. 16:251-338.

Benson-Amram S, Heinen VK, Dryer SL, Holekamp KE. 2011. Numerical assessment and individual call discrimination by wild spotted hyaenas (Crocuta crocuta). Anim Behav. 82:743-752.

Boydston EE, Morelli TL, Holekamp KE. 2001. Sex differences in territorial behavior exhibited by the spotted hyena (Crocuta crocuta). Ethology. 107:369-385.

Butler MJ, Ballard WB, Whitlaw HA. 2006. Physical characteristics, hematology, and serum chemistry of free-ranging gray wolves (Canis lupus) in south-central Alaska. Can Field Nat. 120:205-202.

Cafazzo S, Valsecchi P, Bonanni R, Natoli E. 2010. Dominance in relation to age, sex, and competitive contexts in a group of free-ranging domestic dogs. Behav Ecol. 21:443-455.

Cant M, Otali E, Mwanguhya F. 2002. Fighting and mating between groups in a cooperatively breeding mammal, the banded mongoose. Ethology. 108:541-555.

Caraco T, Wolf LL. 1975. Ecological determinants of group sizes of foraging lions. Am Nat. 109:343-352. 
Cheney DL. 1981. Intergroup encounters among free-ranging vervet monkeys. Folia Primatol (Basel). 35:124-146.

Cooper S. 1991. Optimal hunting group size: the need for lions to defend their kills against loss to spotted hyaenas. Afr J Ecol. 29:130-136.

Creel S, Creel NM. 1995. Communal hunting and pack size in African wild dogs (Lycaon pictus). Anim Behav. 50:1325-1339.

Croofoot MC, Gilby IC, Wikelski MC, Kays RW. 2008. Interaction location outweighs the competitive advantage of numerical superiority in Cebus capucinus intergroup contests. Proc Natl Acad Sci USA. 105:577-581.

Cubaynes S, MacNulty DR, Stahler DR, Quimby KA, Smith DW, Coulson T. 2014. Density-dependent intraspecific aggression regulates survival in northern Yellowstone wolves (Canis lupus). J Anim Ecol. 83:1344-1356.

Davies NB. 1978. Ecological questions about territorial behaviour. In: Krebs JR, Davies NB, editors. Behavioural ecology: an evolutionary approach. Sunderland (MA): Sinauer. p. 317-350.

Doolan S, Macdonald D. 1996. Dispersal and extra-territorial prospecting by slender-tailed meerkats (Suricata suricatta) in the south-western Kalahari. J Zool. 240:59-73.

Fashing PJ. 2001. Activity and ranging patterns of guerezas in the Kakamega forest: intergroup variation and implications for intragroup feeding competition. Int J Primatol. 22:549-577.

Gese EM. 2001. Territorial defense by coyotes (Canis latrans) in Yellowstone National Park, Wyoming: who, how, where, when, and why. Can J Zool. 79:980-987.

Goodall J. 1986. The chimpanzees of Gombe: patterns of behavior. Cambridge (MA): Harvard University Press.

Hayes LD. 2000. To nest communally or not to nest communally: a review of rodent communal nesting and nursing. Anim Behav. 59:677-688.

Hyman J, Hughes M, Searcy WA, Nowicki S. 2004. Individual variation in the strength of territory defense in male song sparrows: correlates of age, territory tenure, and neighbor aggressiveness. Behaviour. 141:15-27.

Johnsson JI, Forser A. 2002. Residence duration influences the outcome of territorial conflicts in brown trout (Salmo trutta). Behav Ecol Sociobiol. 51:282-286.

Kaczensky P, Hayes RD, Promberger C. 2005. Effect of raven Corvus corax scavenging on the kill rates of wolf Canis lupus packs. Wildlife Biol. 11:101-108.

Kemp DJ, Wiklund C. 2004. Residency effects in animal contests. Proc R Soc Lon B Biol Sci. 271:1707-1712.

Krebs JR. 1982. Territorial defence in the great tit (Parus major): do residents always win? Behav Ecol Sociobiol. 11:185-194.

Kruuk H. 1972. The spotted hyena: a study of predation and social behavior. Chicago (IL): University of Chicago Press.

Latham ADM, Boutin S. 2012. Wolf, Canis lupus, pup mortality: interspecific predation or non-parental infanticide? Can Field Nat. 125:158-161.

Lazaro-Perea C. 2001. Intergroup interactions in wild common marmosets (Callithrix jacchus): territorial defence and assessment of neighbours. Anim Behav. 62:11-21.

MacCormick HA, MacNulty DR, Bosacker AL, Lehman C, Bailey A, Collins DA, Packer C. 2012. Male and female aggression: lessons from sex, rank, age, and injury in olive baboons. Behav Ecol. 23:684 691.

MacNulty DR, Smith DW, Vucetich JA, Mech LD, Stahler DR, Packer C. 2009. Predatory senescence in ageing wolves. Ecol Lett. 12:1347-1356.

MacNulty DR, Smith DW, Mech LD, Vucetich JA, Packer C. 2012. Nonlinear effects of group size on the success of wolves hunting elk. Behav Ecol. 23:75-82.

MacNulty DR, Smith DW, Mech LD, Eberly LE. 2009. Body size and predatory performance in wolves: is bigger better? J Anim Ecol. 78:532-539.

Majolo B, Ventura R, Koyama NF. 2005. Sex, rank and age differences in the Japanese macaque (Macaca fuscata yakui) participation in intergroup encounters. Ethology. 111:455-468.

Manson JH, Wrangham RW, Boone JL, Chapais B, Dunbar R, Ember CR, Irons W, Marchant L, McGrew W, Nishida T. 1991. Intergroup aggression in chimpanzees and humans. Curr Anthropol. 32:369-390.

Marden JH, Waage JK. 1990. Escalated damselfly territorial contests are energetic wars of attrition. Anim Behav. 39:954-959.

Marhenke P. 1971. An observation of four wolves killing another wolf. J Mammal. 52:630-631.

Maynard Smith J. 1982. Evolution and the theory of games. Cambridge: Cambridge University Press.

McComb K, Packer C, Pusey A. 1994. Roaring and numerical assessment in contests between groups of female lions, Panthera leo. Anim Behav. $47: 379-387$
Mech LD. 1966. The wolves of Isle Royale. National Park Service Fauna Series No. 7. Washington (DC): U.S. Government Printing Office.

Mech LD. 1970. The wolf: the ecology and behavior of an endangered species. Garden City (NY): Natural History Press.

Mech LD. 1977. Productivity, mortality, and population trends of wolves in northeastern Minnesota. J Mammal. 58:559-574.

Mech LD. 1993. Details of a confrontation between two wild wolves. Can J Zool. 71:1900-1903.

Mech LD. 1994. Buffer zones of territories of gray wolves as regions of intraspecific strife. J Mammal. 75:199-202.

Mech LD. 2006. Age-related body mass and reproductive measurements of gray wolves in Minnesota. J Mammal. 87:80-84.

Mech LD, Adams LG, Meier TJ, Burch JW, Dale BW. 1998. The wolves of Denali. Minneapolis (MN): University of Minnesota Press.

Mech LD, Boitani L. 2003. Wolves: behavior, ecology, and conservation. Chicago (IL): University of Chicago Press.

Mech LD, Frenzel LD. 1971. Ecological studies of the timber wolf in northeastern Minnesota. St. Paul (MN): North Central Forest Experiment Station, Forest Service, US Dept. of Agriculture.

Mitani JC, Watts DP, Amsler SJ. 2010. Lethal intergroup aggression leads to territorial expansion in wild chimpanzees. Curr Biol. 20:507-508.

Mosser A, Packer C. 2009. Group territoriality and the benefits of sociality in the African lion, Panthera leo. Anim Behav. 78:359-70.

Mota M, Abrahão A, Oliveira H. 2005. Genetic and environmental parameters for racing time at different distances in Brazilian thoroughbreds. J Anim Breed Genet. 122:393-399.

Muller MN, Wrangham RW. 2009. Sexual coercion in primates and humans: an evolutionary perspective on male aggression against females. Cambridge (MA): Harvard University Press.

Murie A. 1944. The wolves of Mount McKinley. National Park Service Fauna Series No. 5. Washington (DC): U.S. Government Printing Office.

Packer C, Herbst L, Pusey AE, Bygott JD, Hanby JP, Cairns SJ, Mulder MB. 1988. Reproductive success of lions. In: Clutton-Brock TH, editor. Reproductive success: studies of individual variation in contrasting breeding systems. Chicago (IL): University of Chicago Press. p. 363-383.

Packer C, Scheel D, Pusey AE. 1990. Why lions form groups: food is not enough. Am Nat. 136:1-19.

Pal SK, Ghosh B, Roy S. 1998. Agonistic behaviour of free-ranging dogs (Canis familiaris) in relation to season, sex and age. Appl Anim Behav Sci. 59:331-348.

Peek JM, Van Ballenberghe V, Miquelle DG. 1986. Intensity of interactions between rutting bull moose in central Alaska. J Mammal. 67:423-426.

Pusey AE, Packer C. 1994. Infanticide in lions: consequences and counterstrategies. In: Parmagiani S, Vom Saal FS, editors. Infanticide and parental care. London: Routledge. p. 277-299.

Rodman PS. 1981. Inclusive fitness and group size with a reconsideration of group sizes in lions and wolves. Am Nat. 118:275-283.

Rood JP. 1983. The social system of the dwarf mongoose. In: Eisenberg JF, Kleiman DG, editors. Advances in the study of animal behavior. Lawrence (KS): American Society of Mammalogists (Special Publication 7). p. $454-488$.

Schaller GB. 1972. The Serengeti lion: a study of predator-prey relations. Chicago (IL): University of Chicago Press.

Schmidt PA, Mech LD. 1997. Wolf pack size and food acquisition. Am Nat. 150:513-517.

Schoener TW. 1971. Theory of feeding strategies. Annu Rev Ecol Evol Syst. 2:369-404.

Sikes RS, Gannon WL. 2011. Guidelines of the American Society of Mammalogists for the use of wild mammals in research. J Mammal. 92:235-253

Smith DW, Bangs EE. 2009. Reintroduction of wolves to Yellowstone National Park: history, values, and ecosystem restoration. In: Hayward MW, Somers M, editors. Reintroduction of top-order predators. Oxford: Wiley-Blackwell. p. 92-125.

Smith DW, Bangs EE, Oakleaf JK, Mack C, Fontaine J, Boyd D, Jimenez M, Pletscher DH, Niemeyer CC, Meier TJ, et al. 2010. Survival of colonizing wolves in the Northern Rocky Mountains of the United States, 1982-2004. J Wildl Manage. 74:620-634.

Smith DW, Stahler DR, Albers E, McIntyre R, Metz M, Irving J, Raymond R, Anton C, Cassidy-Quimby K, Bowersock N. 2011. Yellowstone Wolf Project, annual report, 2010. Yellowstone National Park, Mammoth Hot Springs (WY): Yellowstone Center for Resources, YCR-2011-06.

Smith DW, Stahler DR, Albers E, Metz M, Williamson L, Ehlers N, Cassidy K, Irving J, Raymond R, Almberg E, et al. 2009. Yellowstone Wolf 
Project: annual report, 2008. Yellowstone National Park (WY): National Park Service, Yellowstone Center for Resources, YCR-2009-03.

Stahler DR. 2011. Reproductive consequences of sex, age, and kin composition of gray wolf packs. Chapter 3 in Life history, social dynamics, and molecular ecology of Yellowstone wolves [PhD dissertation]. [Los Angeles (CA)]: University of California.

Stahler DR, MacNulty DR, Wayne RK, vonHoldt B, Smith DW. 2013. The adaptive value of morphological, behavioural and life-history traits in reproductive female wolves. J Anim Ecol. 82:222-234.

Tanaka H, Seals DR. 2008. Endurance exercise performance in Masters athletes: age-associated changes and underlying physiological mechanisms. J Physiol. 586:55-63.

Täubert H, Agena D, Simianer H. 2007. Genetic analysis of racing performance in Irish greyhounds. J Anim Breed Genet. 124:117-123.

vonHoldt BM, Stahler DR, Smith DW, Earl DA, Pollinger JP, Wayne RK 2008. The genealogy and genetic viability of reintroduced Yellowstone grey wolves. Mol Ecol. 17:252-274.

Vucetich JA, Peterson RO, Waite TA. 2004. Raven scavenging favours group foraging in wolves. Anim Behav. 67:1117-1126.
Watts DP, Mitani JC. 2001. Boundary patrols and intergroup encounters in wild chimpanzees. Behaviour. 138:299-327.

Williams GC. 1966. Adaptation and natural selection. Princeton (NJ): Princeton University Press.

Wilmers CC, Stahler DR, Crabtree RL, Smith DW, Getz WM. 2003. Resource dispersion and consumer dominance: scavenging at wolf and hunter killed carcasses in greater Yellowstone, USA. Ecol Lett. 6:996-1003.

Wilson ML, Hauser MD, Wrangham RW. 2001. Does participation in intergroup conflict depend on numerical assessment, range location, or rank for wild chimpanzees? Anim Behav. 61:1203-1216.

Wilson ML, Kahlenberg SM, Wells R, Wrangham RW. 2012. Ecological and social factors affect the occurrence and outcomes of intergroup encounters in chimpanzees. Anim Behav. 83:277-291.

Wilson ML, Wrangham RW. 2003. Intergroup relations in chimpanzees. Annu Rev Anthropol. 1:363-392.

Wrangham RW. 1999. Evolution of coalitionary killing. Am J Phys Anthropol. 42:1-30. 